\title{
Respecting Elders by Respecting Their Paid Caregivers
}

\author{
Rebecca L. Sudore, $M^{1,2}$ and Kenneth E. Covinsky, MD, MPH ${ }^{1,2}$ \\ ${ }^{1}$ San Francisco Veterans Affairs Medical Center, San Francisco, CA, USA; ²Division of Geriatrics University of California, San Francisco, CA, USA.
}

J Gen Intern Med 26(5):464-5

DOI: $10.1007 / \mathrm{s} 11606-011-1667-\mathrm{Z}$

(c) The Author(s) 2011. This article is published with open access at Springerlink.com

$\mathrm{T}$ he vast majority of older persons will need to be cared for by another person in their final years of life. A recent UK study demonstrated that $55 \%$ of persons over age 85 in their last year of life were moderately to severely cognitively impaired, 63\% needed help bathing, 43\% needed help dressing, $67 \%$ could walk no further than their home gate, and $50 \%$ needed help with their medications. ${ }^{1}$ Despite popular media hype offering the promise of longevity free of disability as a reward for healthy living, the vast majority of our elderly patients, parents, grandparents, and even those of us who live to old age will need a caregiver for a short period or even years at the end of life. How do we want our frail elderly patients and family members to be treated? The quality of their lives depends upon the quality of their caregiving. If we want our elders to be treated with the respect and dignity they deserve, we need to make sure those who care for them are treated with the respect and dignity they deserve.

Although some frail elders may require care in a nursing home, the majority live at home with family, friends, or paid caregiver support. $^{2}$ Even families who care for their loved ones at home often need supplemental help from paid caregivers given the demands of work and other family responsibilities. ${ }^{3}$ Recent evidence has shown that caring for a loved one with a disability is highly stressful and impacts families emotionally, physically, and economically. ${ }^{4,5}$ Less attention has been paid to the burden placed on paid caregivers, whether they are up to the task, and also importantly, whether they are treated with dignity and respect.

In order to adequately care for one's medical needs, or for another person's, it is essential that the individual have adequate health literacy, defined as the capacity to obtain, process, and understand basic health information to make appropriate heath decisions. ${ }^{6}$ This is particularly important for managing medications. The prevalence of inadequate health literacy in the US population has been estimated to be $46 \%$, with $38 \%$ of adults over age 50 testing in the very lowest health literacy category. ${ }^{7}$ Levels of health literacy are affected by limited education, cognitive impairment, as well as language-related barriers. Many clinicians are unaware of the health literacy of their patients, much less the health literacy of patients' family or non-family paid caregivers. ${ }^{8}$

In this issue of JGIM, Lindquist and colleagues demonstrate

Published online March 18, 2011 the novel finding that $36 \%$ of paid, non-familial caregivers hired privately or through an agency were found to have limited health literacy. ${ }^{9}$ From a population-based standpoint, this rate is not surprising, as this closely mimics the population prevalence of inadequate health literacy. ${ }^{7}$ On the other hand, one would expect a paid health care worker to have better health literacy than the average population, especially since $82 \%$ of caregivers in this study reported prior caregiving experience. Perhaps even more important, $60 \%$ of caregivers made errors when they were asked to read and interpret medication labels and to fill pill boxes. This is concerning, as many paid caregivers are asked to assist with medication management. Yet what was equally noteworthy was that those caring for our vulnerable frail elders are very vulnerable themselves. Approximately $40 \%$ of caregivers had only attained a high school education or less, $63 \%$ were born outside of the US, over $50 \%$ had no family support in the US, and $26 \%$ were paid under the minimum wage. The disenfranchised appear to be caring for the disenfranchised.

We agree with Lindquist that the safety of the elderly is of paramount importance and that caregivers should have access to adequate training. Paid caregivers often allow patients' families to continue to work outside of the home, provide for their families (including the next generation), and contribute to their communities and to the economy. The value of paid caregiving services, often provided by dedicated immigrant workers, should be respected by recognizing that these workers are deserving of appropriate training and compensation. If caring for our elderly population is a moral and societal mission, we also need to respect and value the individuals we pay to care for them. What does this mean? An important aspect of valuing a worker is giving them the assistance and training they need to do their work well and grow professionally.

The authors suggest that potential caregivers could be given a "simple test" to demonstrate competency in health-related tasks such as medication management. We agree that caregivers of frail elders should demonstrate competency in the basic tasks they will perform, such as medication management. However, the most important attributes of a great caregiver are not literacy skills. They are much harder to define attributes such as caring, compassion, empathy, patience, and dedication. Many of the tasks caregivers perform, such as providing transportation, accompanying patients to doctor appointments, preparing food, doing household chores, and providing personal care such as assistance with bathing, are much more dependent on these humanistic attributes than on literacy skills. While these humanistic skills are not teachable, many caregivers who might initially fail a health literacy test can be trained to effectively manage medications and perform other health-related tasks.

The failure to inadequately complete some medication tasks on testing does not mean these caregivers are incapable of 
these tasks. It more likely means that they need to be trained to complete these tasks. There is evidence that low literate individuals can be trained to understand health information and properly use and dose their medications. ${ }^{10-12}$ There is no reason to believe that paid caregivers cannot also be similarly taught with relatively modest efforts. Thus, the point of testing a potential caregiver's health literacy should not be to make a hiring decision, but to identify training needs in persons who have the capacity to be outstanding caregivers. Beyond medication management skills, other skills that can be tested and improved with training include management of difficult behaviors in patients with dementia, prevention of skin breakdown, evaluation for depression, and management of activity of daily living (ADL) dependence.

Lindquist's findings have important implications for physicians. We cannot adequately care for patients without knowing who is taking care of the patient. We cannot assume that the paid caregiver accompanying our patients can dose the medications we are prescribing or that they have been adequately trained by the agency that hired them. Health literacy experts recommend that universal clear health communication be given to all patients regardless of their level of health literacy. ${ }^{6,13}$ It is known that even highly literate individuals often misunderstand health information, as did $57 \%$ of literate caregivers who could not adequately dose pyrantel in this study. Therefore, clear health communication efforts should be extended to all family and non-family, paid caregivers, not just those with limited literacy. In addition, information may need to be presented in the caregiver's native language, not just the patient's.

For health care professionals, it may be prudent to: (1) ask if there is a paid caregiver; (2) include them when medication instructions are given; (3) use teach-back methods with the caregiver similar to those used for low-literate patients; ${ }^{10}$ and (4) obtain help to set up pill boxes for the patients if these services are available. For health care agencies, basic education should be mandated for all employees at the time of hiring, such as how to read a medication prescription and how to fill a pill box as well as how to manage difficult behaviors, prevent skin breakdown, evaluate for depression, manage activities of daily living, and manage their own emotional reactions to caring for very sick patients. For families who are hiring a paid caregiver for their loved one, it is reasonable to expect to give caregivers some training on medication administration and follow-up help if needed.

Paid caregivers are essential participants in a vital social mission to provide compassionate care to vulnerable frail elders who may otherwise need to leave their homes and move to a long-term care setting without their efforts. Although their wages are low, their incomes are often essential for the support of their own families. They also take a great burden off of patients' families. Lindquist's findings are a very valuable contribution because they show that without adequate training, these caregivers may not be able to manage medications and other health-related tasks to care for frail elders adequate- ly. However, many caregivers who may fail a health literacy assessment may still have the potential to be excellent caregivers. It is time to respect the work these caregivers provide by giving them the training necessary to do this work well and the compensation that they deserve. The moral imperative of treating frail elders with respect and dignity needs to come full circle by also treating their very hardworking and dedicated caregivers with respect and dignity.

Open Access: This article is distributed under the terms of the Creative Commons Attribution Noncommercial License which permits any noncommercial use, distribution, and reproduction in any medium, provided the original author(s) and source are credited.

Corresponding Author: Rebecca L. Sudore, MD; San Francisco Veterans Affairs Medical Center, 4150 Clement Street, 181G, San Francisco, CA 94122, USA (e-mail: rebecca.sudore@ucsf.edu).

\section{REFERENCES}

1. Zhao J, Barclay S, Farquhar M, Kinmonth AL, Brayne C, Fleming J. The oldest old in the last year of life: population-based findings from Cambridge city over-75s cohort study participants aged 85 and older at death. J Am Geriatr Soc. 2010;58:1-11.

2. Ness J, Ahmed A, Aronow ws. Demographics and payment characteristics of nursing home residents in the United States: a 23-year trend. J Gerontol A Biol Sci Med Sci. 2004;59:1213-7.

3. Covinsky KE, Eng C, Lui LY, et al. Reduced employment in caregivers of frail elders: impact of ethnicity, patient clinical characteristics, and caregiver characteristics. J Gerontol A Biol Sci Med Sci. 2001;56:M70713.

4. Covinsky KE, Newcomer R, Fox P, et al. Patient and caregiver characteristics associated with depression in caregivers of patients with dementia. J Gen Intern Med. 2003;18:1006-14.

5. Levine C. The loneliness of the long-term care giver. N Engl J Med. 1999;340:1587-90.

6. Institute of Medicine. Health literacy: A Prescription to End Confusion. Washington DC: National Academic Press; 2004.

7. Paasche-Orlow MK, Parker RM, Gazmararian JA, Nielsen-Bohlman LT, Rudd RR. The prevalence of limited health literacy. J Gen Intern Med. 2005;20:175-84.

8. Seligman HK, Wang FF, Palacios JL, et al. Physician notification of their diabetes patients' limited health literacy. A randomized, controlled trial. J Gen Intern Med. 2005;20:1001-7.

9. Lindquist LA, Jain N, Tam K, Martin GJ, Baker DW. Inadequate Health Literacy Among Paid Caregivers of Seniors. J Gen Intern Med 2011.

10. Paasche-Orlow MK, Riekert KA, Bilderback A, et al. Tailored education may reduce health literacy disparities in asthma self-management. Am J Respir Crit Care Med. 2005;172:980-6.

11. Dewalt DA, Malone RM, Bryant ME, et al. A heart failure selfmanagement program for patients of all literacy levels: A randomized, controlled trial [ISRCTN11535170]. BMC Health Serv Res. 2006;6:30.

12. Wallace AS, Seligman HK, Davis TC, et al. Literacy-appropriate educational materials and brief counseling improve diabetes self-management. Patient Educ Couns. 2009;75:328-33.

13. Paasche-Orlow MK, Wolf MS. Evidence does not support clinical screening of literacy. J Gen Intern Med. 2008;23:100-2. 